\title{
Cultured bovine granulosa cells rapidly lose important features of their identity and functionality but partially recover under long-term culture conditions
}

\author{
Vengala Rao Yenuganti ${ }^{1} \cdot$ Jens Vanselow $^{1}$
}

Received: 30 September 2016 / Accepted: 5 January 2017 / Published online: 2 February 2017

(C) The Author(s) 2017. This article is published with open access at Springerlink.com

\begin{abstract}
Cell culture models are essential for the detailed study of molecular processes. We analyze the dynamics of changes in a culture model of bovine granulosa cells. The cells were cultured for up to 8 days and analyzed for steroid production and gene expression. According to the expression of the marker genes $\mathrm{CDH1}, \mathrm{CDH} 2$ and VIM, the cells maintained their mesenchymal character throughout the time of culture. In contrast, the levels of functionally important transcripts and of estradiol and progesterone production were rapidly downregulated but showed a substantial up-regulation from day 4 . FOXL2, a marker for granulosa cell identity, was also rapidly down-regulated after plating but completely recovered towards the end of culture. In contrast, expression of the Sertoli cell marker $S O X 9$ and the lesion/inflammation marker PTGS2 increased during the first 2 days after plating but gradually decreased later on. We conclude that only long-term culture conditions ( $>4$ days) allow the cells to recover from plating stress and to re-acquire characteristic granulosa cell features.
\end{abstract}

Keywords Cell plating $\cdot$ Cell identity $\cdot$ FOXL2 $\cdot$ SOX9 . PTGS2

Electronic supplementary material The online version of this article (doi:10.1007/s00441-017-2571-6) contains supplementary material, which is available to authorized users.

Jens Vanselow

vanselow@fbn-dummerstorf.de

Institute of Reproductive Biology, Leibniz Institute for Farm Animal Biology (FBN), Wilhelm-Stahl-Allee 2,

18196 Dummerstorf, Germany

\section{Introduction}

Granulosa cells are essentially involved in the production of various endocrine- and paracrine-acting hormones such as inhibin, follistatin and estradiol (E2). In order to analyze molecular processes within granulosa cells under diverse pathophysiological conditions, the establishment of appropriate culture models is required. During the last two decades, several different culture systems have been described and used for detailed molecular studies. In the bovine, Gutierrez et al. (1997) established a serum-free follicle-stimulating hormone (FSH)-responsive E2-producing granulosa cell culture system. Moreover, later studies clearly showed that considerable E2 secretion and the expression of corresponding key transcripts by these cells could only be observed under serumfree culture conditions plus FSH and insulin-like growth factor-1 (IGF-1) stimulation (Hamel et al. 2005; Silva and Price 2000). In another study, serum supplementation was demonstrated to induce proliferation but reduced or abolished steroid production and the expression of functionally important genes (Baufeld and Vanselow 2013). To validate a culture model, the functionality and identity of the cells need to be assessed based on physiological and molecular characteristics. Granulosa cells are of mesenchymal origin and express $\mathrm{CDH} 2$ (cadherin 2) and VIM (vimentin), whereas oocytes express the epithelial cell marker CDH1 (cadherin 1; Mora et al. 2012). During follicular growth and differentiation, the proper regulation of genes, such as CYP19Al encoding cytochrome P450, family 19 , subfamily A, polypeptide 1, CCND2 encoding cyclin-D2, FSHR encoding follicle-stimulating hormone receptor and LHCGR encoding luteinizing hormone/ choriogonadotropin receptor and of other genes that are important for granulosa cell function (Gonzalez-Robayna et al. 2000; Park et al. 2005; Law et al. 2013) is essential. Expression of CYP19A1, the key gene of estradiol production, 
is regulated by various factors such as FOXL2 encoding forkhead box protein L2 and NR5A2 encoding nuclear receptor subfamily 5 , group A, member 2 , together with FSH signaling (Sahmi et al. 2014). FOXL2 has emerged as a key factor of ovarian biology. Granulosa cells maintain their identity by expressing FOXL2 and repressing the Sertoli cell marker SOX9 encoding SRY-box 9 (Georges et al. 2014; Uhlenhaut et al. 2009). Knockdown of FOXL2 leads to the loss of granulosa cell identity and the gain of Sertoli cell properties (Uhlenhaut et al. 2009; Ottolenghi et al. 2007). Moreover, FOXL2 regulates the expression of other functionally important genes such as ESR 2 encoding estrogen receptor 2 and FST encoding follistatin.

Until now, our knowledge about the dynamics of changes that are induced by the dissociation, plating and culture of granulosa cells has been limited. This knowledge is however an important pre-requisite for appropriately designing in vitro experiments with cultured granulosa cells. Therefore, during the present study, we analyzed the progressive changes in the physiological and molecular characteristics in an estrogenactive granulosa cell culture model. The production of the steroids E2 and P4 (progesterone) and the expression of marker genes for granulosa cell functionality and identity were analyzed over 8 days and compared with those of freshly isolated cells.

\section{Materials and methods}

\section{Culture of granulosa cells}

The chemicals and antibodies used are shown in the Electronic Supplementary Material (Materials and Methods S1).

Granulosa cells were cultured as previously described (Baufeld and Vanselow 2013; Yenuganti et al. 2016). The cells were aspirated from small to medium-sized follicles $(2-6 \mathrm{~mm}$ in diameter) from slaughterhouse material and plated on collagen-coated 24 -well plates with $1.25 \times 10^{5}$ viable cells (as determined by the trypan blue exclusion method) per well. This isolation procedure enabled nearly pure granulosa cells to be obtained with no contaminating theca cells (Nimz et al. 2009). Cells were grown for up to 8 days in serum-free $\alpha$-MEM containing L-glutamine $(2 \mathrm{mM})$, sodium bicarbonate $(0.084 \%)$, bovine serum albumin (BSA; 0.1\%), HEPES (20 mM), sodium selenite $(4 \mathrm{ng} / \mathrm{ml})$, transferrin $(5 \mu \mathrm{g} / \mathrm{ml})$, insulin $(10 \mathrm{ng} / \mathrm{ml})$, non-essential amino acids (1 mM), penicillin (100 IU) and streptomycin $(0.1 \mathrm{mg} / \mathrm{ml})$ with FSH $(20 \mathrm{ng} / \mathrm{ml})$ and IGF-1 $(25 \mathrm{ng} / \mathrm{ml})$ stimulation and androstenedione $(2 \mu \mathrm{M})$ supplementation at $37{ }^{\circ} \mathrm{C}$ in a $5 \% \mathrm{CO}_{2}$ atmosphere. Media containing all supplements were replaced every other day.

\section{RNA isolation, cDNA synthesis and real-time reverse transcription polymerase chain reaction}

Fore RNA isolation, attached cells were washed once with phosphate-buffered saline (PBS) before lysis. Total RNA was isolated by the Nucleo Spin RNA II Kit (MachereyNagel, Düren, Germany) and quantified with a NanoDrop1000 Spectrophotometer (Thermo Scientific, Bonn, Germany). The cDNA was prepared by using the SensiFAST cDNA Synthesis Kit from 200 ng RNA (Bioline, Luckenwalde, Germany).

Transcript abundance levels were measured by real-time reverse transcription polymerase chain reaction (qPCR) and calculated relative to TBP (TATA-binding protein) housekeeping transcripts (Baddela et al. 2014) for normalization. qPCR was performed with SensiFast SYBR No-ROX (Bioline) and gene-specific primers (see Electronic Supplementary Material, Table S1) in a Light Cycler 96 instrument (Roche, Mannheim, Germany) as described previously (Baddela et al. 2014; Yenuganti et al. 2016). Normalized qPCR values were then expressed as fold changes relative to the respective transcript abundance found in freshly isolated cells.

\section{Western blotting}

After being washed twice with $500 \mu \mathrm{l}$ PBS, the cells were scraped off from culture wells in $500 \mu \mathrm{l}$ PBS, subsequently centrifuged at 135 relative centrifugal force (rcf) for $2 \mathrm{~min}$, washed with PBS, collected in $500 \mu \mathrm{l}$ PBS and centrifuged again at $135 \mathrm{rcf}$ for $2 \mathrm{~min}$. Cell pellets were re-suspended in $50 \mu \mathrm{l}$ RIPA buffer and sonicated (LABSONIC M, Sartorius, Göttingen, Germany) at 0.5 cycles and an amplitude of $30 \%$ for $2 \times 20$ times with a few seconds break. The suspension was centrifuged at 18,400 rcf for $2 \mathrm{~min}$ and the protein concentration of the supernatants was measured by a Micro BCAProtein Assay Kit. Proteins were separated on $12.5 \%$ polyacrylamide gels $(0.75 \mathrm{~mm})$ by electrophoresis at $20 \mathrm{~mA}$ (stacking gel) and $30 \mathrm{~mA}$ (separating gel). The gels were electro-transferred to Immobilon-P Membrane for $60 \mathrm{~min}$ at $1 \mathrm{~mA} / \mathrm{cm}^{2}$ in a Pierce fast semi-dry blotter apparatus (Dreieich, Germany). The membranes were then washed with TBST (TRIS-buffered saline and Tween 20) containing $0.1 \%$ Tween, blocked in a SNAP protein detection system (Millipore) with $30 \mathrm{ml}$ blocking solution $(0.5 \%$ milk powder with TBST), washed three times with $30 \mathrm{ml}$ TBST and incubated with FOXL2 $(1.5 \mu \mathrm{g} / \mathrm{ml})$ and SOX9 (1:1000 dilution) antibodies in TBST with 5\% BSA and incubated at $4{ }^{\circ} \mathrm{C}$ overnight. The membranes were then washed three times with $30 \mathrm{ml}$ TBST each for $10 \mathrm{~min}$, incubated with the secondary antibody in blocking solution (1:3000) for $90 \mathrm{~min}$ at room temperature and washed with $30 \mathrm{ml}$ TBST (three times each) for $10 \mathrm{~min}$. To detect the proteins, $5 \mathrm{ml}$ 
Amershan ECL prime Western blotting detection reagent was added to the membranes, which were then incubated for $5 \mathrm{~min}$ and exposed to X-ray films. The films were developed for $1 \mathrm{~min}$, subsequently washed for $30 \mathrm{~s}$ in water and fixed for 2 min. After a drying step, the images were captured by Raytest (Isotopenmeßgeräte, Staubenhardt, Germany).

\section{Quantification of E2 and P4}

For the determination of steroids, conditioned media were removed from individual wells. Concentrations of E2 and P4 in conditioned culture media were quantified as described previously (Schneider and Brüssow 2006; Baufeld and Vanselow 2013; Yenuganti et al. 2016). Details of the assays are shown in the Electronic Supplementary Material (Materials and Methods S1). E2 and P4 values were expressed relative to the amounts of total RNA isolated from individual samples as a surrogate for the respective cell numbers.

\section{Statistical analysis}

All experiments were carried out three times independently and all data were analyzed by one-way analysis of variance (ANOVA) following Tukey's multiple comparison test by using GraphPad prism 5.0 software.

\section{Results}

\section{Effects of plating on steroid hormone production}

Hormone analysis showed that relative E2 and P4 values were low up to day 4 but that they strongly and significantly increased from day 6 (Table 1). The absolute E2 values in conditioned media after 8 days was $123.3 \pm 5.7 \mathrm{ng} / \mathrm{ml}$ (mean \pm SEM), which is similar to concentrations found in the follicular fluid of bovine dominant E2 active follicles (Nimz et al. 2009), whereas the respective $\mathrm{P} 4$ values $(788.7 \pm 38.9 \mathrm{ng} / \mathrm{ml})$ were much higher than those found in vivo before the preovulatory luteinizing hormone (LH) surge.

\section{Effects of plating on abundance of functionally important transcripts}

To elucidate whether plating induced a mesenchymal to epithelial transition, we analyzed the expression of mesenchymal $(C D H 2$ and VIM) and epithelial $(C D H 1)$ markers. $C D H 1$ was down-regulated in cultured cells as compared with the freshly isolated cells with the lowest levels from day 6 . The expression of $\mathrm{CDH} 2$ was up-regulated with the highest levels at day 1 and 2 but reduced levels similar to those found in freshly isolated cells were detected later on. In contrast, the levels of VIM were not regulated under culture conditions with almost similar levels in cultured and freshly isolated cells (Fig. 1a-c).

An appropriate response to gonadotropins is essential for the function of granulosa cells. Therefore, we comparatively measured the expression levels of FSHR and LHGCR in freshly isolated and in plated granulosa cells. Levels of FSHR transcripts rapidly decreased after plating and continuously increased from day 2 but did not reach the levels found in freshly isolated cells. Moreover, the expression of LHCGR transcripts rapidly decreased after plating and started to increase later on. However, in contrast to FSHR, the abundance of LHCGR transcripts reached and even exceeded the level of that in freshly isolated cells after 6 days (Fig. 1d, e).

As a paradigm for steroid hormone production, we analyzed the expression of steroidogenic acute regulatory protein $(S T A R)$ and of CYP19A1 (Fig. 1f, g). In addition, we analysed the expression of the nuclear receptor $N R 5 A 2$, which regulates several functionally important genes in granulosa cells, such as $C C N D 2$, which is involved in the regulation of granulosa cell proliferation (Robker and Richards 1998), FST, which is involved in feedback regulation between brain and ovary and PTGS2, which is essential for ovulation. CYP19A1, NR5A2, $C C N D 2$ and $F S T$ were rapidly down-regulated, with CYP19A1 decreasing to nearly undetectable levels after cell plating (Fig. 1g-j). Subsequently, a continuous up-regulation of these transcripts was observed from days 2 or 4 . However, in particular, CYP19A1 transcripts but also NR5A2 and FST transcripts, did not reach the original levels found in freshly isolated granulosa cells. In contrast, STAR and PTGS2 transcripts (Fig. 1f, k) showed higher expression in cultured granulosa cells. However, whereas the abundance of STAR transcripts continuously increased from day 4 , the expression of PTGS2 was rapidly up-regulated after plating but subsequently declined. Estrogens and androgens exert their action on granulosa cells via various receptors, namely estrogen receptor 1 (ESR1), estrogen receptor 2 (ESR2) and androgen receptor $(A R)$. The analysis of the respective transcripts showed an initial decrease and a continuous increase after plating (Fig. 11-n).

\section{Expression of marker transcripts and proteins of granulosa and sertoli cell identity}

Because of the very low initial CYP19A1 expression and E2 production in cultured cells as compared with those in freshly isolated samples, we analyzed the mRNA and protein expression of markers of granulosa and sertoli cell identity, namely FOXL2 and $S O X 9$, respectively. Interestingly, FOXL2 expression was reduced but that of $S O X 9$ was increased after plating. However, whereas the expression of FOXL2 rapidly 
Table 1 Estradiol $(E 2)$ and progesterone $(P 4)$ concentrations relative to total RNA content in conditioned media from granulosa cells after various culture periods (different superscripts indicate significantly different means \pm standard errors; $P<0.05$; one-way ANOVA)

\begin{tabular}{|c|c|c|c|c|c|}
\hline Hormone & 1 day & 2 days & 4 days & 6 days & 8 days \\
\hline E2/RNA & $0.35 \pm 0.08^{\mathrm{a}}$ & $0.38 \pm 0.10^{\mathrm{a}}$ & $0.72 \pm 0.05^{\mathrm{a}}$ & $2.35 \pm 0.59^{\mathrm{b}}$ & $3.28 \pm 0.23^{\mathrm{b}}$ \\
\hline P4/RNA & $4.99 \pm 0.70^{\mathrm{A}}$ & $5.03 \pm 0.89^{\mathrm{A}}$ & $8.69 \pm 0.55^{\mathrm{A}, \mathrm{B}}$ & $13.00 \pm 0.50^{\mathrm{B}}$ & $23.21 \pm 3.23^{C}$ \\
\hline
\end{tabular}

decreased and slowly recovered, thus reaching similar levels as those observed in freshly isolated granulosa cells, the levels of $S O X 9$ were low in freshly isolated granulosa cells but increased after plating and decreased again towards the end of culture (Fig. 2).

\section{Discussion}

To our knowledge, the present study describes, for the first time, the dynamics of changes that are induced by the dissociation, plating and culture of granulosa cells based not only on physiological characteristics but also on numerous marker genes that are important for the identity, structure and functionality of granulosa cell. In contrast to previous studies, our presented set of data also allows a direct comparison of the in vitro data with the data derived from original in vivo material, i.e., freshly isolated cells.

The present results showed that some plated granulosa cells strongly changed their expression levels of some marker genes. However, the decreased expression of the epithelial marker $C D H 1$ but the constant or even increased expression of the mesenchymal markers VIM and $C D H 2$, respectively, clearly suggest that aspirated granulosa cells maintain their mesenchymal character under the present culture conditions and do not shift towards an epithelial phenotype.

In contrast, our data clearly indicate that plating severely and rapidly compromises granulosa cell functionality, in particular during the first few days in culture. The levels of gonadotropin receptor transcripts, namely FSHR and LHCGR and in particular those of CYP19A1 immediately and strongly decreased, with those of CYP19A1 being reduced to nearly negligible levels during the first 2 days in culture. Later on, the cells continuously started to re-express these genes but only in the case of LHCGR did the transcript levels reach and even exceed those found in freshly isolated granulosa cells. The dynamics of CYP19A1 expression is also clearly in agreement with E2 production showing an increase from very low levels directly after plating to its highest levels at the end of culture. Moreover, the levels of P4 gradually increased with time in culture. However, the final levels were much higher than the corresponding E2 levels. This is in concordance with the remarkably increased expression of STAR, which is involved in the first step of steroid hormone biosynthesis. On the other hand, this also suggests that the cells display some properties of luteinized granulosa cells, which are characterized by a huge increase of $\mathrm{P} 4$ production. However, the simultaneous ability of the cells to produce E2 at physiological levels clearly contradicts the notion that the cells have passed the folliculo-luteal transition phase but instead suggests that they might be arrested at an intermediate stage even after long-term culture.

In bovine granulosa cells, the activation of CYP19A1 expression has been shown to require FSH stimulation and the presence of the transcription factors FOXL2 and NR5A2 (Sahmi et al. 2014). Interestingly, the expression of FSHR, NR5A2 and FOXL2 was also rapidly down-regulated after plating, thus suggesting that this might in turn cause the down-regulation of CYP19A1 transcripts and of E2 production. In addition, the levels of $C C N D 2$ and $L H C G R$ that are also regulated by FSH signaling were transiently downregulated directly after plating.

Previous reports have shown that FOXL2 is important for maintaining granulosa cell identity, whereas $S O X 9$ is described as a Sertoli cell marker (Georges et al. 2014; Uhlenhaut et al. 2009). FOXL2 expression was low in our culture system directly after plating, with the lowest levels at day 2 and gradually increased from day 4 . At the same time, the expression of $S O X 9$ was stimulated after plating, thus reaching a maximum level at day 2 , before it was subsequently down-regulated. This suggests that reduced levels of FOXL2 expression after plating allow an increased expression of SOXY and thus might induce a transient loss of granulosa cell identity and a gain of Sertoli cell characteristics. In contrast, genes whose expression is usually stimulated by FOXL2, such as FST (Georges et al. 2014), were down-regulated.

Fig. 1 Abundance levels of functionally important transcripts in freshly isolated and cultured granulosa cells. Abundance levels of different transcripts (a-n) are shown in freshly isolated (Fresh) and plated granulosa cells after various culture periods (days 1 to 8 ). Different letters indicate significantly different changes (mean fold changes \pm standard errors; $P<0.05$; one-way analysis of variance [ANOVA] from three independent experiments) relative to freshly isolated cells 

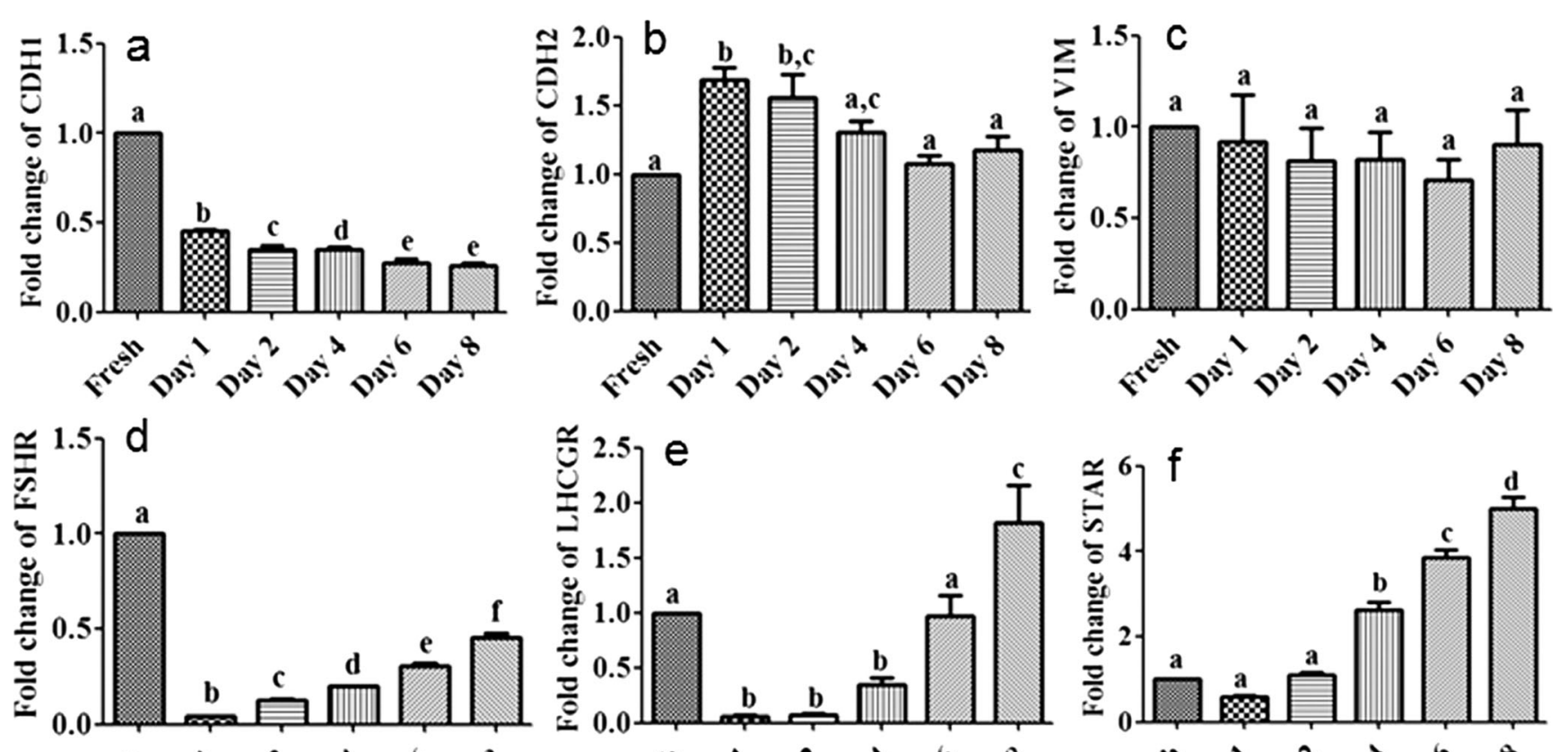

s.
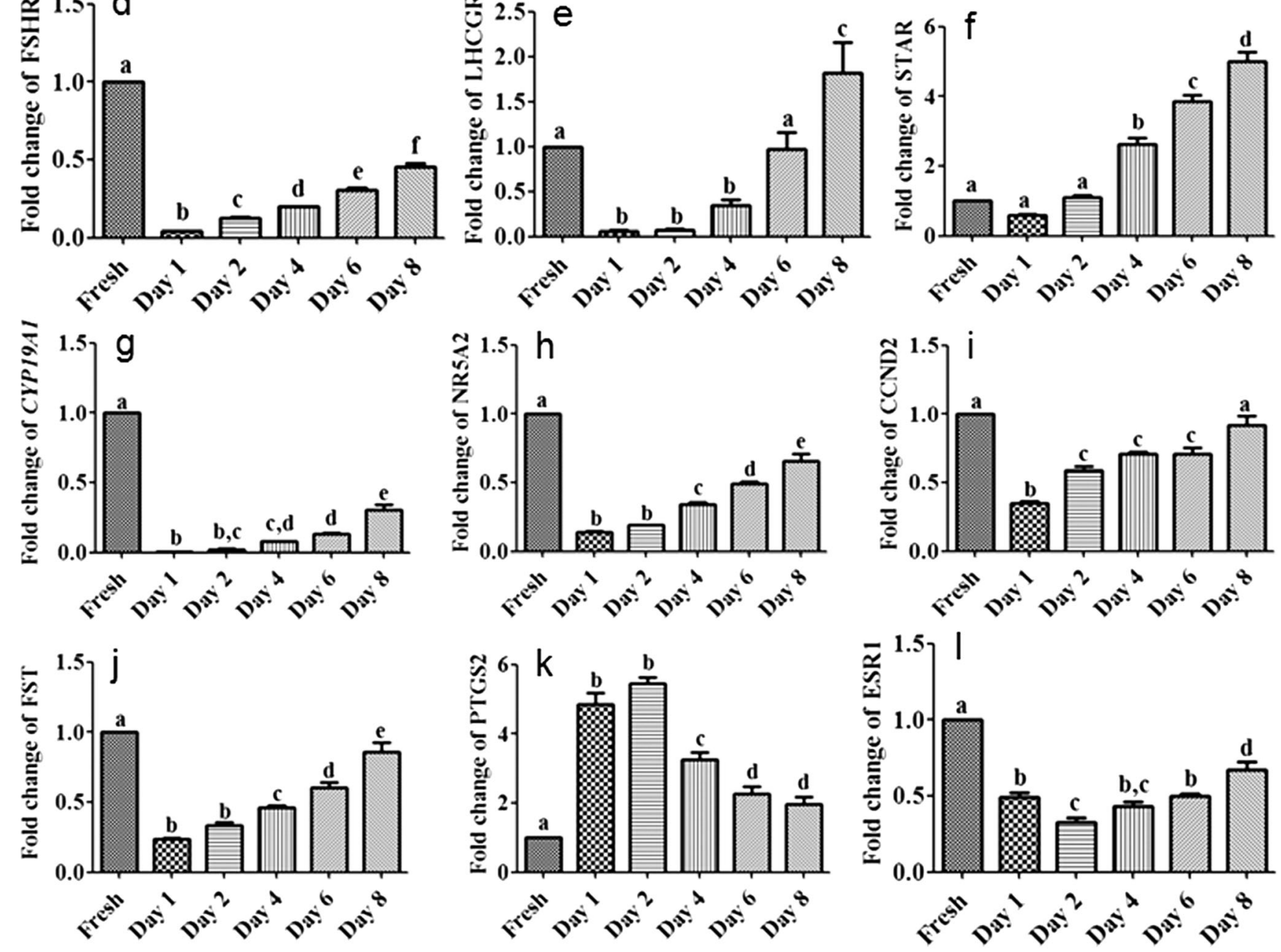

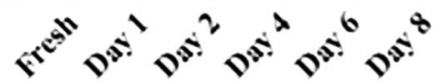
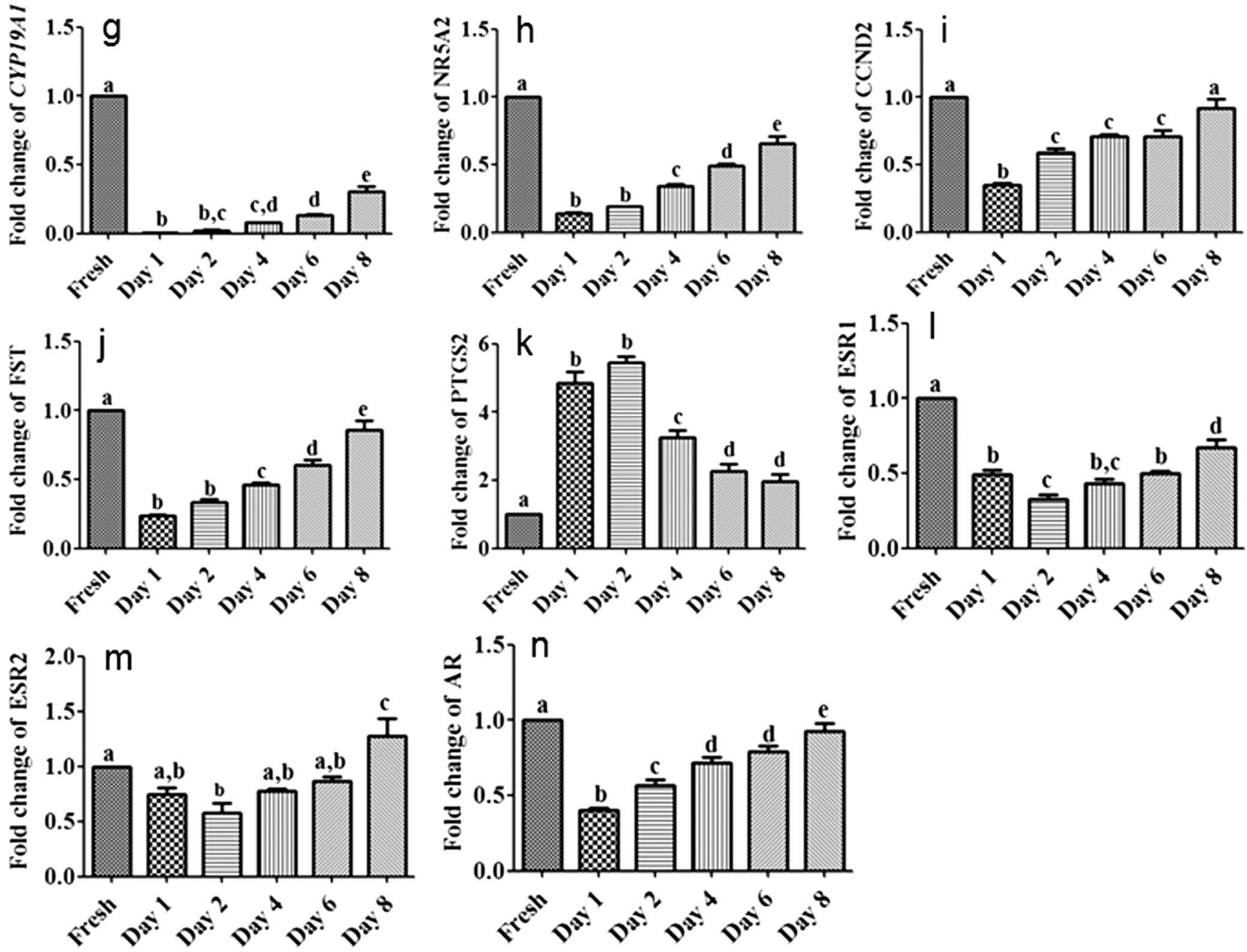
Fig. 2 Transcript and protein abundance of FOXL2 and SOX9 in freshly isolated and cultured granulosa cells. Transcript and protein abundance of FOXL2 (a, b) and of the Sertoli cell marker $\mathrm{SOX} 9(\mathbf{c}, \mathbf{d})$ as determined by RTqPCR (a, c) and immunoblotting (b, d; representative blots). Different letters indicate significant differences of fold changes (mean fold change \pm standard error; $P<0.05$; one-way ANOVA from three independent experiments) relative to freshly isolated cells

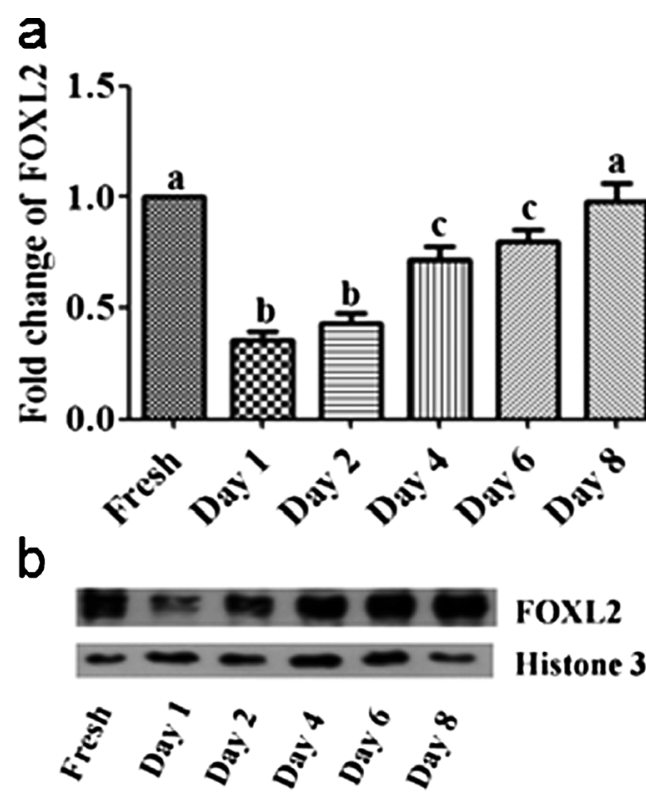

C

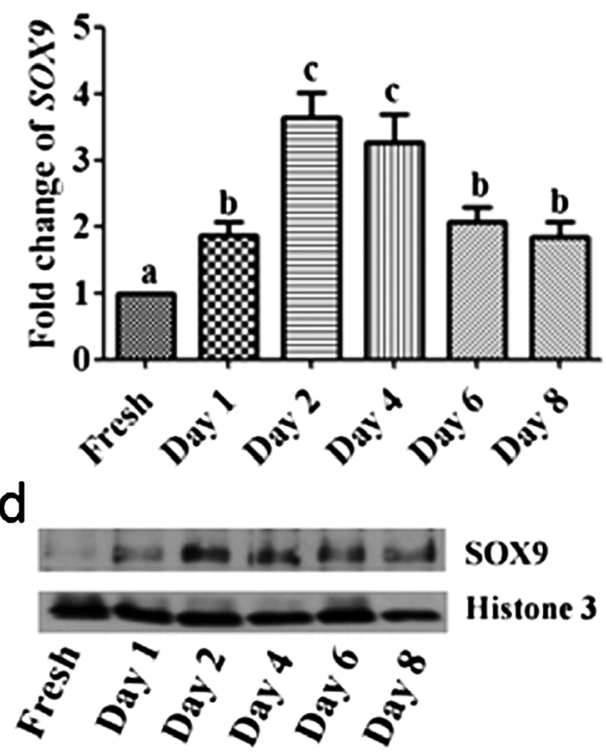

Estradiol exerts its actions via the nuclear receptors, ESR 1 and ESR2. In the bovine, ESR 2 mRNA and protein are present in granulosa cells (Rosenfeld et al. 1999). Our data showed that ESR2 was initially down-regulated after cell plating, with a minimum at day 2 , before it was continuously up-regulated towards the end of culture. ESR1 expression rapidly decreased in plated granulosa cells but, in contrast to ESR2, did never reach its original levels as observed in freshly isolated cells. The temporal expression pattern of ESR 2 paralleled the expression of FOXL2 but not that of ESR1. Georges et al. (2014) showed that ESR2 is essential for estradiol-mediated signaling in granulosa cells. These data suggest that the plating of bovine granulosa cells will, at least during the first few days in culture, reduce the E2 responsiveness of these cells. Moreover, the levels of $A R$ were rapidly down-regulated after plating but subsequently recovered up to day 8 . Sen and Hammes (2010) demonstrated that mice with granulosa-cell-specific $A R$ knockout exhibit severe ovarian defects. This adds to our conclusion that granulosa cell functionality is severely compromised during the first few days after plating.

Follistatin is a glycoprotein that binds to activin and inhibits its activity (Shimasaki et al. 1989), thus acting as an inhibitor of FSH secretion from the pituitary (Robertson et al. 1987; Ueno et al. 1987). In addition to these endocrine actions, follistatin is known to be able to act as a paracrine or autocrine antagonist of activin within the bovine follicle. FST transcripts are highly up-regulated in large estrogen-active follicles (Glister et al. 2011). The immediate down-regulation of FST transcript abundance after plating and slow recovery under long-term culture conditions again suggests that bovine granulosa cells rapidly lose important molecular properties under culture conditions but can recover these properties several days later.

Interestingly, our results showed a rapid rise and subsequent decrease of PTGS2 expression with levels near to those found in freshly isolated cells. In vivo PTGS2 expression is considered as a reliable marker for approaching ovulation (Sirois 1994). PTGS2 encodes COX-2, which is the key enzyme in prostaglandin biosynthesis. In addition to its role in ovulation, the expression of this enzyme is induced after lesions or inflammatory reactions. Accordingly, the rapid and transient upregulation of PTGS2 after plating can be interpreted as the result of a cellular stress reaction attributable to the dissociation and plating procedure. Its down-regulation several days later might therefore, in turn, indicate that the cells have largely recovered from the initial stress.

From our results, we conclude that, after being plated, granulosa cells rapidly but transiently, lose important features of their identity and functionality as indicated by the down-regulation of functionally important genes. Moreover, the transient up-regulation of the stress marker PTGS2 and of the Sertoli cell marker SOX9 supports this view. However, after long-term culture, those markers that are important for granulosa cell functionality gradually increase, whereas those that compromise granulosa cell function, such as the Sertoli cell and stress/ inflammation markers, gradually decrease towards day 8. Accordingly, under the present culture conditions, the cells need at least 4 days to recover from the plating stress thus suggesting that granulosa cells cultured for only 4 days or less might not be an appropriate in vitro model to analyze granulosa cell function. 
Acknowledgements We are grateful to Veronica Schreiter, Maren Anders, Gesine Krüger and Swanhild Rodewald for their technical support.

\section{Compliance with ethical standards}

Conflict of interest The authors declare that they have no conflict of interest.

Open Access This article is distributed under the terms of the Creative Commons Attribution 4.0 International License (http:// creativecommons.org/licenses/by/4.0/), which permits unrestricted use, distribution, and reproduction in any medium, provided you give appropriate credit to the original author(s) and the source, provide a link to the Creative Commons license, and indicate if changes were made.

\section{References}

Baddela VS, Baufeld A, Yenuganti VR, Vanselow J, Singh D (2014) Suitable housekeeping genes for normalization of transcript abundance analysis by real-time RT-PCR in cultured bovine granulosa cells during hypoxia and differential cell plating density. Reprod Biol Endocrinol 12:118

Baufeld A, Vanselow J (2013) Increasing cell plating density mimics an early post-LH stage in cultured bovine granulosa cells. Cell Tissue Res 354:869-880

Georges A, L'Hote D, Todeschini AL, Auguste A, Legois B, Zider A, Veitia RA (2014) The transcription factor FOXL2 mobilizes estrogen signaling to maintain the identity of ovarian granulosa cells. Elife 3:e04207 doi:10.7554/eLife.04207

Glister C, Satchell L, Knight PG (2011) Granulosal and thecal expression of bone morphogenetic protein- and activin-binding protein mRNA transcripts during bovine follicle development and factors modulating their expression in vitro. Reproduction 142:581-591

Gonzalez-Robayna IJ, Falender AE, Ochsner S, Firestone GL, Richards JS (2000) Follicle-stimulating hormone (FSH) stimulates phosphorylation and activation of protein kinase $\mathrm{B}$ (PKB/Akt) and serum and glucocorticoid-lnduced kinase (Sgk): evidence for A kinaseindependent signaling by FSH in granulosa cells. Mol Endocrinol 14:1283-1300

Gutierrez CG, Campbell BK, Webb R (1997) Development of a longterm bovine granulosa cell culture system: induction and maintenance of estradiol production, response to follicle-stimulating hormone, and morphological characteristics. Biol Reprod 56:608-616

Hamel M, Vanselow J, Nicola ES, Price CA (2005) Androstenedione increases cytochrome $\mathrm{P} 450$ aromatase messenger ribonucleic acid transcripts in non-luteinizing bovine granulosa cells. Mol Reprod Dev 70:175-183

Law NC, Weck J, Kyriss B, Nilson JH, Hunzicker-Dunn M (2013) Lhcgr expression in granulosa cells: roles for PKA-phosphorylated betacatenin, TCF3, and FOXO1. Mol Endocrinol 27:1295-1310

Mora JM, Fenwick MA, Castle L, Baithun M, Ryder TA, Mobberley M, Carzaniga R, Franks S, Hardy K (2012) Characterization and significance of adhesion and junction-related proteins in mouse ovarian follicles. Biol Reprod 86:153

Nimz M, Spitschak M, Schneider F, Fürbass R, Vanselow J (2009) Downregulation of genes encoding steroidogenic enzymes and hormone receptors in late preovulatory follicles of the cow coincides with an accumulation of intrafollicular steroids. Domest Anim Endocrinol $37: 45-54$

Ottolenghi C, Pelosi E, Tran J, Colombino M, Douglass E, Nedorezov T, Cao A, Forabosco A, Schlessinger D (2007) Loss of Wnt4 and Foxl2 leads to female-to-male sex reversal extending to germ cells. Hum Mol Genet 16:2795-2804

Park Y, Maizels ET, Feiger ZJ, Alam H, Peters CA, Woodruff TK, Unterman TG, Lee EJ, Jameson JL, Hunzicker-Dunn M (2005) Induction of cyclin D2 in rat granulosa cells requires $\mathrm{FSH}-$ dependent relief from FOXO1 repression coupled with positive signals from Smad. J Biol Chem 280:9135-9148

Robertson DM, Klein R, de Vos FL, McLachlan RI, Wettenhall RE, Hearn MT, Burger HG, de Kretser DM (1987) The isolation of polypeptides with FSH suppressing activity from bovine follicular fluid which are structurally different to inhibin. Biochem Biophys Res Commun 149:744-749

Robker RL, Richards JS (1998) Hormone-induced proliferation and differentiation of granulosa cells: a coordinated balance of the cell cycle regulators cyclin D2 and p27Kip1. Mol Endocrinol 12:924 940

Rosenfeld CS, Yuan X, Manikkam M, Calder MD, Garverick HA, Lubahn DB (1999) Cloning, sequencing, and localization of bovine estrogen receptor-beta within the ovarian follicle. Biol Reprod 60: 691-697

Sahmi F, Nicola ES, Zamberlam GO, Goncalves PD, Vanselow J, Price CA (2014) Factors regulating the bovine, caprine, rat and human ovarian aromatase promoters in a bovine granulosa cell model. Gen Comp Endocrinol 200:10-17

Schneider F, Brüssow KP (2006) Effects of a preovulatory administered depot gonadotrophin-releasing hormone agonist on reproductive hormone levels and pregnancy outcome in gilts. Reprod Fertil Dev 18:857-866

Sen A, Hammes SR (2010) Granulosa cell-specific androgen receptors are critical regulators of ovarian development and function. Mol Endocrinol 24:1393-1403

Shimasaki S, Koga M, Buscaglia ML, Simmons DM, Bicsak TA, Ling N (1989) Follistatin gene expression in the ovary and extragonadal tissues. Mol Endocrinol 3:651-659

Silva JM, Price CA (2000) Effect of follicle-stimulating hormone on steroid secretion and messenger ribonucleic acids encoding cytochromes P450 aromatase and cholesterol side-chain cleavage in bovine granulosa cells in vitro. Biol Reprod 62:186-191

Sirois J (1994) Induction of prostaglandin endoperoxide synthase-2 by human chorionic gonadotropin in bovine preovulatory follicles in vivo. Endocrinology 135:841-848

Ueno N, Ling N, Ying SY, Esch F, Shimasaki S, Guillemin R (1987) Isolation and partial characterization of follistatin: a single-chain Mr 35,000 monomeric protein that inhibits the release of folliclestimulating hormone. Proc Natl Acad Sci U S A 84:8282-8286

Uhlenhaut NH, Jakob S, Anlag K, Eisenberger T, Sekido R, Kress J, Treier AC, Klugmann C, Klasen C, Holter NI, Riethmacher D, Schutz G, Cooney AJ, Lovell-Badge R, Treier M (2009) Somatic sex reprogramming of adult ovaries to testes by FOXL2 ablation. Cell 139:1130-1142

Yenuganti VR, Viergutz T, Vanselow J (2016) Oleic acid induces specific alterations in the morphology, gene expression and steroid hormone production of cultured bovine granulosa cells. Gen Comp Endocrinol 232:134-144 